\title{
Factors associated with patient satisfaction in an outpatient hospital pharmacy
}

\author{
Noemí Martínez-López-de-Castro, Miriam Álvarez-Payero, Alicia Martín-Vila, \\ Marisol Samartín-Ucha, Patricia Iglesias-Neiro, Mónica Gayoso-Rey, \\ Débora Feijoo-Meléndez, Cristina Casanova-Martínez, Miguel Fariña-Conde, \\ Guadalupe Piñeiro-Corrales
}

\begin{abstract}
- Additional material is published online only. To view please visit the journal online (http://dx.doi.org/ 10.1136/ejhpharm-2016001192)
\end{abstract}

Pharmacy Department, EOXI, Vigo, Spain

\section{Correspondence to} Noemí Martínez-López-deCastro; noemi.martinez. lopezdecastro@sergas.es

Received 15 December 2016 Revised 16 February 2017 Accepted 20 February 2017 Published Online First 16 March 2017

\section{Check for updates}

To cite: Martínez-López-deCastro N, Álvarez-Payero M,

Martín-Vila A, et al.

Eur J Hosp Pharm

2018:25:183-188

\section{ABSTRACT}

Objective To analyse the factors leading to greater satisfaction among patients attending the outpatient hospital pharmacy (OPh).

Methods A cross-sectional study was conducted of patients attending the OPh of a 1250-bed university hospital. A self-administered questionnaire for measuring outpatients' satisfaction was developed. Global satisfaction was measured on a scale of 1 to 10. Indices of perceived quality for accessibility, interpersonal professional-patient relationship and the convenience of the process were modelled through a principal component analysis using varimax rotation. The relationship between the principal components and overall satisfaction was evaluated using regression analysis.

Results A questionnaire-based survey was conducted between May and June 2015. A total of 509 valid responses (86.9\% response rate) were collected from the OPh. The overall satisfaction score was 7.81 (95\% Cl 7.59 to 8.04). The principal component analysis produced two components that explained $62.1 \%$ of the variance. The first component (CP1) contained questions related to the adequacy of the resources and services. The second component (CP2) contained questions about interpersonal professional-patient relationship. An additional unit in the CP2 was associated with a 3.23 increased risk of having higher satisfaction scores, while an increase of an additional unit in CP1 was associated with a 1.93 increased risk of having higher satisfaction scores.

Conclusions Our study shows that the factor which predicts the satisfaction of patients who come to the $\mathrm{OPh}$ is the quality of care provided by pharmacists - in particular, information provided, resolution of doubts, personal attention and time devoted to the patient.

\section{INTRODUCTION}

Patient satisfaction with the healthcare process is an important assessment of patient preferences and expectations, none of which can be obtained through external observation. Owing to social transformations and the changing role of health service users, measurement of patient satisfaction has become increasingly important for quality improvement in health systems, ${ }^{1}$ of which the hospital pharmacy services are a part. In collaboration with other health professionals, pharmacists have a responsibility to achieve results that improve the quality of care of patients. ${ }^{23}$

\section{What this paper adds}

What is already known about this subject Patient satisfaction with hospital pharmacist care is generally high with respect to pharmacist's skills, communication and care received.

The worst feature perceived by patients includes organisational aspects, such as pharmacy location, timetable or waiting time in the outpatient hospital pharmacy (OPh).

\section{What this study adds}

To the best of our knowledge this is the first study to examine the association between overall satisfaction and quality aspects perceived by patients attending an $\mathrm{OPh}$.

Quality of care provided by pharmacists - in particular, information, resolution of doubts, personal attention and time devoted to the patient, was a predictor of overall patient satisfaction in the $\mathrm{OPh}$.

The outpatient hospital pharmacy $(\mathrm{OPh})$ is a priority area within the organisation of pharmacy departments in hospitals owing to the increasing number of patients attending and the considerable economic impact that this represents. Proper use of human resources, facilities and financial resources directly affects the quality of care and improved patient health outcomes. ${ }^{4}$

Other studies of patient satisfaction with an $\mathrm{OPh}$ have been published. ${ }^{5-10}$ They generally show a high degree of patient satisfaction with the pharmacist's skills, communication and care received from pharmacists of the $\mathrm{OPh}$. Poorer assessments included organisational aspects such as pharmacy location, timetable or waiting time. However, none of these studies provided information about which factors predict patient satisfaction in the $\mathrm{OPh}$. Research in other healthcare areas has identified a positive association between patient satisfaction 
and healthcare provision indicators, such as nurses and physicians per 100000 habitants, and a negative association between patient satisfaction and number of hospital beds. ${ }^{11}$ Overall satisfaction in a dialysis centre was critically determined by patients' satisfaction with the clinical environment, equipment and treatment. ${ }^{12}$ In a cross-sectional national exit survey of HIV and non-HIV service users in Zambia, favourable perceptions of health personnel conduct were associated with higher scores of overall satisfaction. ${ }^{13}$

Similarly, an evaluation of critical factors, such as individual characteristics, perceptions of pharmacist care provided and facilities in the $\mathrm{OPh}$ area, would help to highlight potential interventions for improving patient satisfaction.

The main objective of our study was to analyse the factors leading to greater satisfaction among patients attending the $\mathrm{OPh}$.

The collected data became part of a computer file complying with Law 15/1999, of December 13, entitled Protection of Personal Data. The data were used exclusively in this research project, remaining completely anonymous and confidential. The study was approved by the South Galicia clinical research ethics committee (human subject application 2015/268).

\section{METHODS}

This observational, descriptive cross-sectional study was conducted in a 1250-bed university hospital. The $\mathrm{OPh}$ covers a population of 600000 inhabitants and is organised into four outpatient pharmacy clinics that see approximately 4500 patients a month (mostly patients with chronic disease).

A questionnaire-based survey was conducted between May and June 2015. The study population comprised patients who came to collect medication at the $\mathrm{OPh}$. Patients with at least three visits to collect medication from any of the $\mathrm{OPh}$ clinics and who voluntarily agreed to participate in the study were included. If a patient was under 18 years old, an eligible attendant was asked to answer the survey. Patients with a lack of understanding or difficulty in answering questions were excluded.

The selection of subjects was made according to the inclusion criteria and in sequential order of arrival, as a sampling non-probabilistic model, to complete the sample size. Sample size was calculated taking into account the populations attending the OPh: 4500 patients come monthly to the OPh. The following assumptions were considered: an accuracy of 5\%, a confidence level of $95 \%$ and an expected satisfaction rate of $50 \%$. Final sample size was calculated at 530 patients.

Based on published scientific evidence, ${ }^{25-8}$ a questionnaire was developed by consensus with a panel of five clinical pharmacists.

The survey contained four sections. The first focused on the sociodemographic profile of the respondents. To capture how patients perceived specific aspects of the facility and their health providers, a second section was included to rate 10 aspects exploring accessibility, interpersonal professional-patient relationship and the convenience of the process. Each item was assessed with a Likert scale, where 1 was the lowest rated response and 5 was the highest. To measure patients' overall satisfaction, a third section was included as a scale. Patients rated their satisfaction on a scale from 1 to 10 , where 1 was least satisfaction and 10 was highest satisfaction with care in the OPh. The fourth section consisted of three closed-end questions about the way in which patients receive information about their medicines. Finally, there was an additional section where the respondents could express their opinions or suggestions. The questionnaire was designed to be anonymous and self-reported. (The survey is published as an online Supplementary file.)
A pilot study was conducted on a random sample of 30 patients (excluded from the final analysis) to evaluate the degree of comprehensibility of the questions and the time needed to respond. The questionnaire was adapted according to the results of the pilot study.

The survey was offered to patients while they were waiting to be seen at the $\mathrm{OPh}$. Investigator pharmacists requested patients' verbal consent and used an informative brochure to explain the purpose of the survey. They also explained that the questionnaire was anonymous and should be deposited in a box located outside the clinic in order to guarantee confidentiality. Patients who refused to answer the survey were asked to deposit the unanswered questionnaire in the box and were excluded from the analysis.

The data were collected in an Excel database by researchers and were analysed using Statistical Packages for Social Sciences (SPSS), version 18. A SE $\beta 95 \%$ and a lower level of significance $\alpha 0.05$ were considered. First, a descriptive analysis was performed to characterise the sample. Correlations were made to ensure adequacy of the subscales. The instrument was assessed for its reliability in the study and had Cronbach's $\alpha$ of 0.868 .

The average score of patient overall satisfaction was calculated using an ordinal variable as a dependent variable and then bivariate correlations were made with other survey items using the $\left(\chi^{2}\right)$ test with adjusted and unadjusted OR $(95 \% \mathrm{CI})$.

A principal component analysis was performed to reduce the size of variables and later to perform an ordinal logistic regression to determine how overall satisfaction (rated from 1 to 10 ) was related to specific aspects of the facility and their health providers measured with the five-point Likert scale.

\section{RESULTS}

Of the 586 surveys distributed among patients attending the $\mathrm{OPh}$ during the study period, 509 were collected, representing a response rate of $86.9 \%$. Table 1 summarises the general characteristics of respondents. Of the survey respondents, 76.2\% were the patient themselves, while $23.8 \%$ were attendants. Of respondents, who were working at the time of the survey, $22.4 \%$ reported having problems attending for scheduled visits; $72.9 \%$ of respondents considered the number of times that they attended the $\mathrm{OPh}$ to be adequate. The overall satisfaction score using a 10-point scale was 7.81 (95\% CI 7.59 to 8.04). In total, $11.4 \%$ of patients gave a satisfaction score of 5 or lower. Table 2 summarises patients' assessment for the each of the 10 specific aspects of care, measured using the Likert scale. The best perceived aspect was staff's personal treatment (93\% 'satisfied' or 'very satisfied'). However, the waiting time, signposting for the $\mathrm{OPh}$ and comfort of the waiting room were the worst rated, with just $55 \%$ of the patients reporting that they were 'satisfied' or 'very satisfied'.

A multivariate logistic regression was performed with sociodemographic characteristics of respondent and the overall satisfaction. After adjusting for confounders, our findings showed that men, respondents who were satisfied with the opening hours of the $\mathrm{OPh}$ and those with no work problems attending the consultations were more likely to be satisfied with the care provided (table 3).

Because there was a correlation between variables, principal component analysis was performed with respect to the items contained in the Likert scale questions. The dimension of variables was reduced to two components that explained $62.1 \%$ of variance. The first component (CP1) grouped variables related to the adequacy of the resources and services, such as appropriate 
Table 1 General characteristics of patients who answered the satisfaction survey

\begin{tabular}{|c|c|c|}
\hline Characteristics & No. of patients & Percentage \\
\hline \multicolumn{3}{|l|}{ Gender } \\
\hline a) Male & 263 & $51.7 \%$ \\
\hline b) Female & 233 & $45.8 \%$ \\
\hline c) No answer & 13 & $2.6 \%$ \\
\hline Age (years), mean $\pm S D$ & $50.16 \pm 12.83$ & \\
\hline \multicolumn{3}{|c|}{ Means of transport for attending OPh: } \\
\hline a) Car & 283 & $55.6 \%$ \\
\hline b) Bus & 143 & $28.1 \%$ \\
\hline c) Taxi & 8 & $1.6 \%$ \\
\hline d) On foot & 59 & $11.6 \%$ \\
\hline e) Other & 10 & $2.0 \%$ \\
\hline f) No answer & 6 & $1.2 \%$ \\
\hline \multicolumn{3}{|l|}{ Time needed to get to the hospital: } \\
\hline a) $<15 \min$ & 107 & $21.0 \%$ \\
\hline b) $15-45 \mathrm{~min}$ & 316 & $62.1 \%$ \\
\hline c) $46-60 \mathrm{~min}$ & 51 & $10.0 \%$ \\
\hline d) $>60 \mathrm{~min}$ & 31 & $6.1 \%$ \\
\hline e) No answer & 4 & $0.8 \%$ \\
\hline \multicolumn{3}{|l|}{ Education: } \\
\hline a) No studies & 13 & $2.6 \%$ \\
\hline b) Elementary school graduate & 195 & $38.3 \%$ \\
\hline c) Middle school graduate & 188 & $36.9 \%$ \\
\hline d) College graduate & 102 & $20.0 \%$ \\
\hline e) No answer & 11 & $2.2 \%$ \\
\hline \multicolumn{3}{|l|}{ Employment status: } \\
\hline a) Working & 168 & $33.0 \%$ \\
\hline b) Pensioner & 174 & $34.2 \%$ \\
\hline c) Unemployed & 69 & $13.6 \%$ \\
\hline d) Housewife/househusband & 53 & $10.4 \%$ \\
\hline e) Student & 13 & $2.6 \%$ \\
\hline f) Medical leave & 21 & $4.1 \%$ \\
\hline g) No answer & 11 & $2.2 \%$ \\
\hline
\end{tabular}

opening hours of the $\mathrm{OPh}$, comfortableness of the waiting room, clear signalling of the $\mathrm{OPh}$, time from medical prescription to dispensation and waiting time. The second component (CP2) grouped variables related to the pharmaceutical care practices and conduct: suitable resolution of patient doubts, appropriate information provided by the pharmacist, pharmacist's time dedicated to the patient and pharmacist's personal treatment of the patient. Figure 1 shows graphically which variable is most represented in each component. The variables waiting time in the waiting room and the confidentiality conditions of the waiting room could not be explained through the principal component analysis. Of these two components, it was observed that the professional's related component was the most predictive factor of patient satisfaction.

Details of the regression analysis are shown in table 4. Specifically, an additional unit in the CP2 is associated with a 3.23 increased risk of having higher satisfaction scores, whereas an increase of an additional unit in CP1 would be associated with only a 1.93 increased risk of having higher satisfaction scores.

The survey included questions about preferences and the current drug information. The results showed that $91.7 \%$ of patients considered the medical staff as the main professionals to inform them about their treatment while $5.2 \%$ of the patients considered the pharmacist as the main professional. In addition, 9.6\% considered both professionals to be at the same level. To receive information about their medicines, $43.6 \%$ of patients preferred oral information, $23 \%$ wanted written information and only $3.3 \%$ of patients preferred the Internet; $18.6 \%$ of the patients considered that it was necessary to have various formats concomitantly available to them. One hundred and twenty-seven respondents $(25.0 \%)$ expressed an opinion in the final section. Twenty-seven comments were positive (all about care provided), 29 were negative opinions (21\% about care provided) and 31 were classified as neutral.

\section{DISCUSSION}

Our study shows that the factor which best predicts the satisfaction of patients who come to the OPh is the quality of care provided by pharmacists-in particular, the information provided, resolution of doubts, personal attention and time devoted to the patient. Facility characteristics, such as the waiting room conditions or signposting, do not directly correlate with improvement in overall patient satisfaction. These data suggest that greater specialisation of the pharmacist in certain areas of knowledge is perceived positively by patients. No differences in patient satisfaction were found in relation to age, means of transport, distance to the hospital and level of education or employment status.

Our results are consistent with those reported in other studies in which the aspects given the highest rating were the experience of the pharmacist ${ }^{7}$ or perceived manner of, and information provided by, the pharmacist. ${ }^{8}$ A cross-sectional study conducted in Canada in 500 patients of five community pharmacies measured perceived pharmacist expertise, relationship quality, self-efficacy, patient satisfaction and relationship commitment. Patient-perceived pharmacist expertise was described as an

Table 2 Results of the assessment of the 10 questions of the Likert scale satisfaction survey (second section): patients' perceptions of specific aspects of care Scoring is as follows: $1=$ very dissatisfied; $2=$ dissatisfied; $3=$ neutral; $4=$ satisfied; $5=$ very satisfied.

\begin{tabular}{|c|c|c|c|c|c|c|}
\hline \multirow[b]{2}{*}{ Survey item } & \multirow[b]{2}{*}{ Number of responses } & \multicolumn{5}{|c|}{ Satisfaction scores } \\
\hline & & 1 & 2 & 3 & 4 & 5 \\
\hline The signs and posters are suitable & 474 & $10.5 \%$ & $14.3 \%$ & $17.1 \%$ & $43.0 \%$ & $15.0 \%$ \\
\hline The waiting room is comfortable and appropriate & 475 & $6.1 \%$ & $13.9 \%$ & $24.6 \%$ & $45.3 \%$ & $10.1 \%$ \\
\hline The opening hours of clinics are appropriate & 472 & $7.6 \%$ & $13.3 \%$ & $10.0 \%$ & $55.3 \%$ & $13.8 \%$ \\
\hline The waiting time for being attended is satisfactory & 470 & $9.6 \%$ & $19.1 \%$ & $16.8 \%$ & $43.6 \%$ & $10.9 \%$ \\
\hline Confidentiality conditions are suitable & 467 & $4.9 \%$ & $1.9 \%$ & $9.2 \%$ & $53.5 \%$ & $30.4 \%$ \\
\hline The time from the prescription until its dispensation in clinic is satisfactory & 471 & $4.5 \%$ & $3.2 \%$ & $8.9 \%$ & $54.1 \%$ & $29.3 \%$ \\
\hline OPh staff's personal treatment is adequate & 475 & $3.2 \%$ & $1.3 \%$ & $2.7 \%$ & $39.2 \%$ & $53.7 \%$ \\
\hline The amount of time that the pharmacist dedicates to me in the clinic is adequate & 475 & $2.7 \%$ & $1.7 \%$ & $5.3 \%$ & $45.3 \%$ & $45.1 \%$ \\
\hline I have been clearly informed about my treatment & 475 & $3.2 \%$ & $2.7 \%$ & $7.8 \%$ & $45.1 \%$ & $41.3 \%$ \\
\hline Any doubts I have raised about my treatment have been resolved & 472 & $3.6 \%$ & $0.8 \%$ & $10.4 \%$ & $44.7 \%$ & $40.5 \%$ \\
\hline
\end{tabular}

$\mathrm{OPh}$, outpatient hospital pharmacy. 


\section{Original article}

Table 3 Ordered logistic regression results examining demographic and visit factors as predictors of overall satisfaction on OPh. Unadjusted and adjusted odds ratios and $95 \% \mathrm{Cl}$

\begin{tabular}{|c|c|c|c|c|}
\hline Respondent's characteristics & & Unadjusted OR $(95 \% \mathrm{CI})$ & Adjusted OR $(95 \% \mathrm{Cl})$ & $\begin{array}{l}\text { Model OR } \\
(95 \% \mathrm{Cl})\end{array}$ \\
\hline Age (years) & $\begin{array}{l}18-40 \\
40-60 \\
>60\end{array}$ & $\begin{array}{l}0.28(0.16 \text { to } 0.49)^{*} \\
0.06(0.36 \text { to } 0.96)^{*} \\
\text { Reference }\end{array}$ & $\begin{array}{l}0.72(0.14 \text { to } 3.77) \\
1.94(0.39 \text { to } 9.56) \\
\text { Reference }\end{array}$ & \\
\hline Gender & $\begin{array}{l}\text { Male } \\
\text { Female }\end{array}$ & $\begin{array}{l}1.29(0.91 \text { to } 1.82) \\
\text { Reference }\end{array}$ & $\begin{array}{l}2.20(1.09 \text { to } 4.45)^{*} \\
\text { Reference }\end{array}$ & $\begin{array}{l}1.31(1.26 \text { to } 4.24)^{*} \\
\text { Reference }\end{array}$ \\
\hline Education & $\begin{array}{l}\text { No studies } \\
\text { Elementary school graduate } \\
\text { Middle school graduate } \\
\text { College graduate }\end{array}$ & $\begin{array}{l}2.29(0.69 \text { to } 7.63) \\
2.49(1.56 \text { to } 3.97)^{*} \\
1.48(0.94 \text { to } 2.34) \\
\text { Reference }\end{array}$ & $\begin{array}{l}1.37(0.13 \text { to } 13.78) \\
2.15(0.86 \text { to } 5.39) \\
1.21(0.54 \text { to } 2.70) \\
\text { Reference }\end{array}$ & \\
\hline Type of transport for attending OPh & $\begin{array}{l}\text { Car } \\
\text { Bus } \\
\text { Taxi } \\
\text { On foot } \\
\text { Other }\end{array}$ & $\begin{array}{l}1.04(0.30 \text { to } 3.63) \\
1.10(0.31 \text { to } 3.88) \\
0.42(0.07 \text { to } 2.59) \\
0.86(0.23 \text { to } 3.23) \\
\text { Reference }\end{array}$ & $\begin{array}{l}0.24(0.01 \text { to } 4.41) \\
0.19(0.01 \text { to } 4.02) \\
0.57(0.00 \text { to } 84.86) \\
0.17(0.01 \text { to } 3.44) \\
\text { Reference }\end{array}$ & \\
\hline Time it took to get to the hospital (min) & $\begin{array}{l}<15 \\
16-30 \\
31-45 \\
46-60 \\
>60\end{array}$ & $\begin{array}{l}1.26(0.58 \text { to } 2.75) \\
1.76(0.84 \text { to } 3.71) \\
1.35(0.61 \text { to } 2.94) \\
2.50(1.02 \text { to } 6.16) \\
\text { Reference }\end{array}$ & $\begin{array}{l}0.41(0.06 \text { to } 2.93) \\
1.00(0.15 \text { to } 6.48) \\
0.50(0.07 \text { to } 3.41) \\
2.57(0.28 \text { to } 23.31) \\
\text { Reference }\end{array}$ & \\
\hline Problems in getting to the hospital & $\begin{array}{l}\text { Yes } \\
\text { No }\end{array}$ & $\begin{array}{l}0.42(0.21 \text { to } 0.84)^{*} \\
\text { Reference }\end{array}$ & $0.20(0.08 \text { to } 0.49)^{*}$ & $0.47(0.23 \text { to } 0.79)^{*}$ \\
\hline Number of times patient comes to the OPh clinics & $\begin{array}{l}\text { Suitable } \\
\text { Excessive } \\
\text { Scarce }\end{array}$ & $\begin{array}{l}1.83(0.41 \text { to } 8.15) \\
0.67(0.15 \text { to } 3.03) \\
\text { Reference }\end{array}$ & $\begin{array}{l}3.18(1.48 \text { to } 6.84)^{*} \\
\text { Reference }\end{array}$ & $\begin{array}{l}3.22(1.70 \text { to } 6.11)^{*} \\
\text { Reference }\end{array}$ \\
\hline
\end{tabular}

${ }^{*}\left(\chi^{2}\right)$, where $p<0.05$

OPh, outpatient hospital pharmacy.

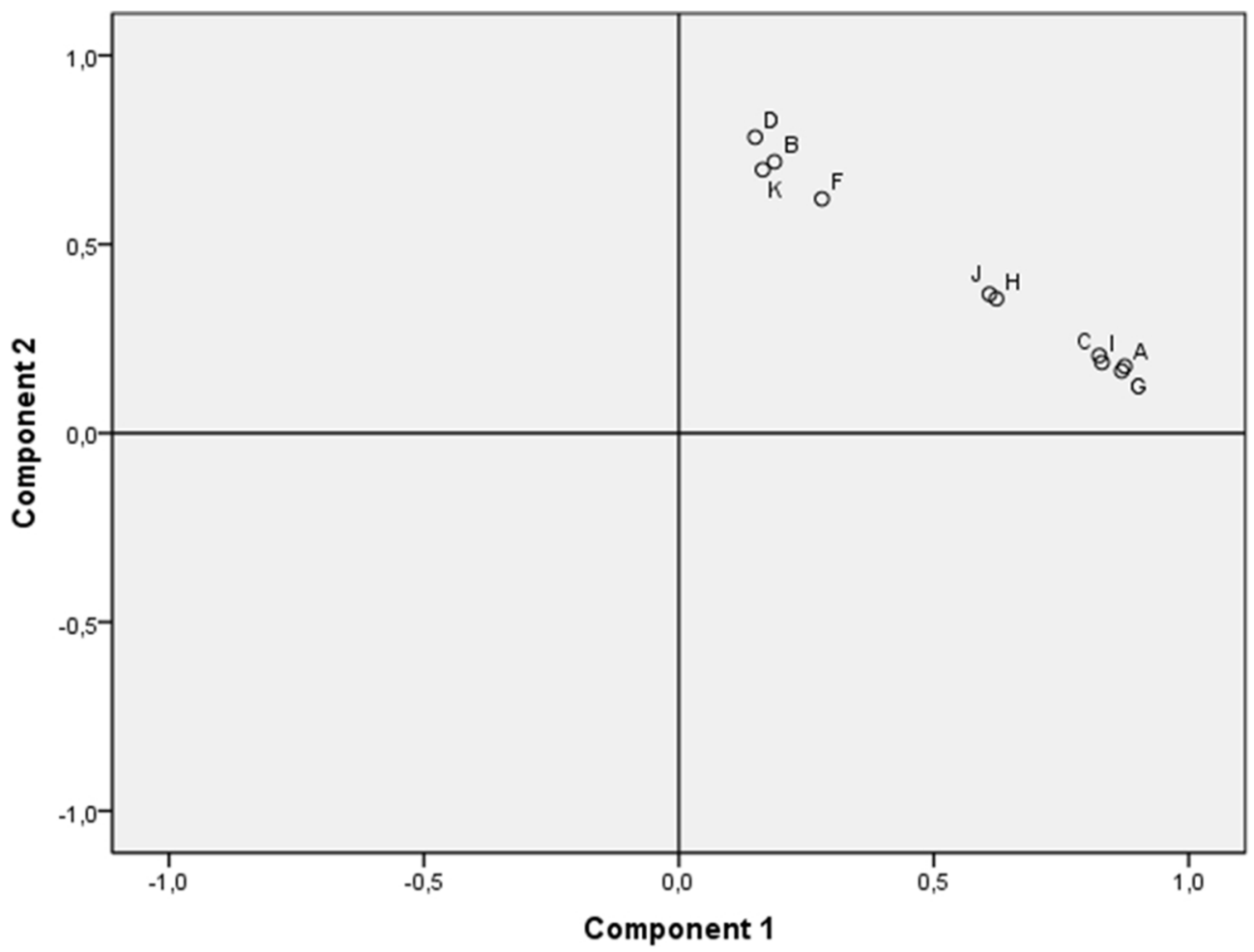

Figure 1 Component plot in rotated space. In the graph the 10 variables are represented according to the varimax rotation. Component 1 is identified with the 'facilities' (variables $A,(C, I, G)$ and component 2 is identified with 'personal treatment' (variables $D,(B, K, F)$. Variables J and H could not be explained through this analysis. The variables are as follows: $A$, suitable resolution of patient doubts; $B$, appropriate opening hours of clinics; $C$, appropriate

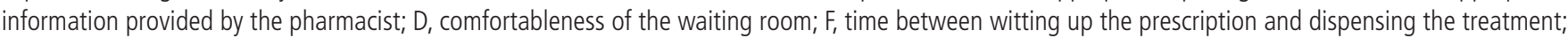
$\mathrm{G}$, pharmacist's time dedicated to the patient; $\mathrm{H}$, period of time patient is in the waiting room; I, pharmacist's personal treatment of the patient; J, comfort of the waiting room; $K$, clear signalling of the outpatient hospital pharmacy. 
Table 4 Regression analysis estimate for all the variables as predictors of patient overall satisfaction

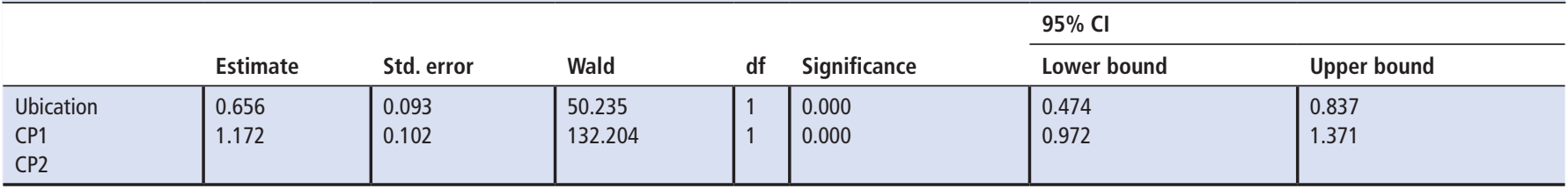

CP1 contains the variables: suitable resolution of patient doubts, appropriate information provided by the pharmacist, pharmacist's personal treatment of the patient and pharmacist's time dedicated to the patient.

CP2 contains the variables: comfort of the waiting room, appropriate opening hours of clinics, time between writing up the prescription and dispensing the treatment and clear signalling of the $\mathrm{OPh}$.

independent factor of patient satisfaction. ${ }^{10}$ Kim et al $l^{9}$ assessed satisfaction with pharmacy services provided though medication therapy management. Patient satisfaction was not significantly different according to age, gender, ethnicity or number of disease states but, satisfaction with the medication therapy management correlated positively with overall patient satisfaction. Hall et al ${ }^{14}$ described and compared patient satisfaction with two different types of care: a pharmacist physician collaborative model and a traditional physician model in a rheumatology clinic setting. Patient satisfaction in the collaborative care group was consistently higher across all dimensions. These results confirm that a positive and expertise interaction with the patient can have an influence on overall satisfaction. Similar results were obtained in the study of Martin and Faber ${ }^{15}$ Patients reported a high level of satisfaction with the clinical pharmacist involved in hepatitis $\mathrm{C}$ virus treatment management.

It is noteworthy, that despite the high satisfaction reported by the patients in our study with the care provided by pharmacists of the $\mathrm{OPh}$, they consider the doctor to be the professional and their main source of information about medicines. Other studies have reported that patients most often recalled the information about adverse drugs effects from physicians (97.2\%), nurses $(60.7 \%)$, inpatient pharmacist $(49 \%)$ or outpatient pharmacist $(44.8 \%))^{16}$ This suggests that the pharmacist should focus on, and attempt to improve, such information to increase the quality of care.

Although technology can be used to obtain information about health, ${ }^{1718}$ in our study, almost $50 \%$ of patients preferred written information, although the mean age was 50 years. This might be explained by the type of population answering the survey, or it might simply be that patients prefer the health system to offer the traditional model of information and, at the same time, still wish to have the technological route available for their own personal use when they want to search for information.

\section{Limitations}

Our findings must be interpreted in the light of the following limitations. First, a notable limitation of this study was that it focused only on patients treated in our hospital. Therefore, the results of this study might not be valid for other health systems. Second, although we conducted a pilot study on 30 patients, there might have been bias in the way in which questions were formulated and written, with problems possibly related to unclear writing or the use of unusual words. Bias might also arise from asking questions that are considered invasive, leading the respondent to become defensive when answering. Third, the questionnaire is not validated for measuring patient satisfaction of $\mathrm{OPh}$ because no available validated survey was available at the time of the study. Finally, it was pharmacist investigators who offered the survey to the patient, which might have potential bias, although patients to were allowed to complete it in private.

\section{CONCLUSION}

Our study shows that the factor predicting the satisfaction of patients who come to the $\mathrm{OPh}$ is the quality of care provided by pharmacists-in particular, the provision of information, resolution of doubts, personal attention and time devoted to the patient. Facility characteristics, such as the waiting room conditions or signposting, do not directly correlate with improvement in overall patient satisfaction. Our findings provide a road map for health providers, indicating which aspects should be prioritised to have the greatest impact on patient overall satisfaction. Health providers should carry out strategies to keep welltrained and incentivised health professionals to treat patients with the highest level of quality. Future studies should determine if greater patient satisfaction has a positive effect on health outcomes, which could result in economic savings.

Contributors NMLDC: Concept and design, Data interpretation \& Writing of manuscript. MÁP: Concept and design, Data interpretation \& Writing of manuscript. AMV: Concept and design, Data interpretation \& Writing of manuscript. MSU: Concept and design \& Revision of manuscript. MGR: Data collection. PIN: Data collection. DFM: Data collection. CCM: Data collection. MFC: Data interpretation. GPC: Revision of manuscript.

Competing interests None declared.

Provenance and peer review Not commissioned; externally peer reviewed.

(c) European Association of Hospital Pharmacists (unless otherwise stated in the text of the article) 2018. All rights reserved. No commercial use is permitted unless otherwise expressly granted.

\section{REFERENCES}

1 Díaz R. Satisfacción del paciente: principal motor y centro de los servicios sanitarios. Revista de Calidad Asistencial 2002;17:22-9.

2 Márquez-Peiró JF, Pérez-Peiró C. [Evaluation of patient satisfaction in outpatient pharmacy]. Farm Hosp 2008;32:71-6.

3 Real Academia nacional de farmacia, ministerio de sanidad y consumo, consejo general de colegios oficiales de farmacéuticos,sociedad española de farmacéuticos de atención primaria (SEFAP), Sociedad española de farmacia comunitaria (SEFAC), Sociedad española de farmacia hospitalaria (SEFH), Fundación pharmaceutical care españa, grupo de investigación en atención farmacéutica de la facultad de granada. documento de consenso del foro de atención farmacéutica. Enero 2008. http://www. msssi.gob.es/profesionales/farmacia/consenso/consenso.htm\#indice (accessed 20 Aug 2016).

4 Barbosa CD, Balp MM, Kulich K, et al. A literature review to explore the link between treatment satisfaction and adherence, compliance, and persistence. Patient Prefer Adherence 2012;6:39-48.

5 Izquierdo-García E, Fernández-Ferreiro Á., Campo-Angora M, et al. Satisfacción percibida por los pacientes y por el personal auxiliar de farmacia del área de atención a pacientes externos como método de mejora de la calidad. Revista de Calidad Asistencial 2011;26:161-7.

6 Antón Torres R, Murcia López A, Borrás Blasco J, et al. [Assessment of quality as perceived by users of an outpatient pharmaceutical care unit]. Farm Hosp 2006;30:99-104

7 Montero A, Feal B, Calvín M, et al. [Quality perceived by outpatients at the pharmaceutical care clinic]. Farm Hosp 2006;30:105-11.

8 Monje-Agudo P, Borrego-Izquierdo Y, Robustillo-Cortés ML, et al. [Design and validation of a satisfaction survey with pharmaceutical care received in hospital pharmacy consultation]. Farm Hosp 2015;39:152-6.

9 Kim S, Martin MT, Pierce AL, et al. Satisfaction with medication therapy management services at a university ambulatory care clinic. J Pharm Pract 2016;29:199-205 
10 Alghurair SA, Simpson SH, Guirguis LM. What elements of the patient-pharmacist relationship are associated with patient satisfaction? Patient Prefer Adherence 2012;6:663-76.

11 Xesfingi S, Vozikis A. Patient satisfaction with the healthcare system: assessing the impact of socio-economic and healthcare provision factors. BMC Health Serv Res 2016;16:94.

$12 \mathrm{Gu} \mathrm{X}$, Itoh K. Factors behind dialysis patient satisfaction: exploring their effects on overall satisfaction. Ther Apher Dial 2015;19:162-70.

13 Dansereau E, Masiye F, Gakidou E, et al. Patient satisfaction and perceived quality of care: evidence from a cross-sectional national exit survey of HIV and non-HIV service users in Zambia. BMJ Open 2015;5:e009700.

14 Hall JJ, Katz SJ, Cor MK. Patient satisfaction with pharmacist-led collaborative followup care in an ambulatory rheumatology clinic. Musculoskeletal Care 2016.
15 Martin MT, Faber DM. Patient satisfaction with the clinical pharmacist and prescribers during hepatitis C virus management. J Clin Pharm Ther 2016:41:645-9.

16 Wilbur K, Al Okka M, Jumat E, et al. Medication risk communication with cancer patients in a middle east cancer care setting. Patient Prefer Adherence 2016;10:613-9.

17 Lee JL, Choudhry NK, Wu AW, et al. Patient use of email, facebook, and physician websites to communicate with physicians: a national online survey of retail pharmacy users. J Gen Intern Med 2016;31:45-51.

18 Andreassen HK, Bujnowska-Fedak MM, Chronaki CE, et al. European citizens' use of E-health services: a study of seven countries. BMC Public Health 2007;7:53. 